
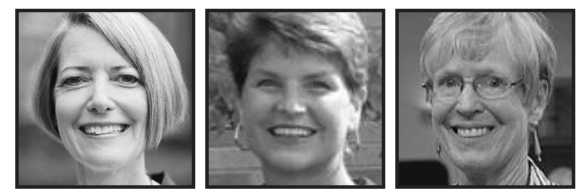

\title{
The Promise of Action Research: Lessons Learned From the Indiana Principal Leadership Institute
}

\author{
Nancy Fichtman Dana, University of Florida \\ Linda Marrs-Morford, Indiana State University \\ Shelley Roberts, University of New Mexico
}

\section{ABSTRACT}

The purpose of this article is to describe a professional development program for principals focused on their engagement in action research, the systematic and intentional study by principals of their own administrative practice. The program is described in detail along with a brief analysis of the action research produced by the principals, a report of the principals' perceptions of the action research experience from survey data, and the authors' reflections on important considerations to take into account when designing a long-term program of principal professional development that endeavors to develop principals as action researchers.

\footnotetext{
$\mathrm{n}$ recent years, there has been increased attention to determining the factors that constitute powerful professional development for teachers and the ways these factors translate into effective models of professional development
} (Desimone, 2009; Garet, Porter, Desimone, Birman, \& Yoon, 2001). While we have learned a great deal about teacher development from these studies and efforts, it is important to note that principals, no less than teachers, need effective models of professional development as well. Mitgang and Gill (2012) call attention to the importance of ongoing support for principal development: "Getting pre-service principal training right is essential. But equally important is the training and support school leadership receive after they're hired" (p. 20). Why is this so important? Study after study documents the significant impact principals have on student achievement 
(e.g., Leithwood, Louis, Anderson, \& Wahlstrom, 2004; Marzano, Waters, \& McNulty, 2005). In a 2010 Wallace Foundation Report, Education Leadership: An Agenda for School Improvement, DeVita says, "The bottom line is that investments in good principals are a particularly cost-effective way to improve teaching and learning" (p. 3).

Yet, professional development for principals has been described as a "wasteland" (Barth, 2001). According to the National Association of Secondary School Principals and National Association of Elementary School Principals report entitled Leadership Matters: What the Research Says About the Importance of Principal Leadership (2013), while some principals have access to meaningful professional development opportunities that provide a well-developed system of support for them as they enact their work as administrators, "others still have to fly by the seat of their pants and feel that the culture is unsupportive" (p. 10).

To help address the many principals who remain unsupported without access to professional development opportunities, recommendations for principal professional development programs have consistently appeared in the literature for the past two decades. For example, the Educational Research Service's (1999) publication Professional Development for School Principals states that, "effective staff development for administrators is long-term, planned, and job-embedded; focuses on student achievement; supports reflective practice; and provides opportunities to work, discuss, and solve problems with peers" (p. 8.3). The Interstate Licensure Consortium made similar recommendations in 2000, in a text entitled, Proposition for Quality Professional Development of School Leaders, and updated these recommendations again in 2008. More recently, Hitt, Tucker, and Young (2012) described the importance of professional development efforts for principals at all levels of experience as focusing on "reflection, growth, and renewal" (p. 11).

Keeping the recommendations made by these reports and other publications on the professional development of principals published over time in mind, the P-12 faculty in the department of Educational Leadership at Indiana State University designed an intensive professional development program for practicing principals. The department received funding from the Indiana Legislature to develop the two-year program, entitled "Indiana Principal Leadership Institute" (IPLI). IPLI seeks to "provide buildinglevel principals with the skills and tools needed to increase their personal leadership capacities, as well as to increase the learning capacities of their schools" (http://www. indianapli.org/). To increase both the personal leadership capacity of principals as well as the learning capacity of their schools, one core feature of IPLI professional development programming is engaging administrators in action research. 
Many exemplary leadership development programs utilize action research as a component of the overall professional development of school principals (DarlingHammond, LaPointe, Meyerson, Orr, \& Cohen, 2007). Adopted from the work on teacher/action research (Cochran-Smith \& Lytle, 2009; Noffke, 1997; Somekh \& Zeichner, 2009; Dana \& Yendol-Hoppey, 2014; Dana, 2013), principal action research refers to the process of a principal engaging in systematic, intentional study of his/her own administrative practice and taking action for change based on what he/she learns as a result of the inquiry (Dana, Tricarico, \& Quinn, 2010; Dana, Thomas, \& Boynton, 2011; Dana, 2009). Inquiring principals begin the process of action research by defining a research question or "wondering" that is based on a current dilemma, problem, issue, or tension they face as an administrator. Next, they develop a plan to gain insights into their question through the collection and analysis of multiple forms of data. Data can include, but is not limited to, the following: classroom walk-through notes, field notes, anecdotal notes, student work, teacher lesson plans, journals kept by the administrator, interviews, surveys, documents produced by the school, student performance on tests and other assessment measures, and literature related to the topic of their study. After data analysis, principals share their learning with others and take action for change based on their learning and begin the action research cycle again.

While IPLI is just entering the third year of its work, the process of action research has shown great promise as one mechanism to create powerful professional learning opportunities for principals that address the recommendations made in the literature. The purpose of this article is to describe the ways action research has been incorporated into IPLI and lessons learned by the authors in the implementation of this model of principal professional learning over time. We begin with a brief overview of the history and structure of IPLI, followed by a detailed description of the ways action research was incorporated into it with a particular focus on the ways action research was introduced and experienced by the principals during their first year of participation in the program. Next, we share a brief analysis of the action research produced by the principals and report on their perceptions of the AR experience from survey data collected on the principals' overall satisfaction with IPLI. Finally, we end this article with our reflections on important considerations to take into account when designing a long-term program of principal professional development that endeavors to develop principals as action researchers. 


\section{Overview of the Indiana Principal Leadership Institute}

Created by the Indiana General Assembly in 2013, IPLI represents a bipartisan effort to strengthen education in Indiana by focusing on how to better prepare and support principals to lead in their schools and their communities. The Department of Educational Leadership at Indiana State University partnered with the Indiana Association of School Principals to establish the two-year institute.

The conceptual framework for the model used to guide this institute is grounded in theory from the literature related to leadership capacity and learning organizations, and is diagrammed in Figure 1. Reflecting the mission of IPLI, the diagram represents the ways action research helps principals build their own personal leadership capacity as well as their school's learning capacity over a two-year timeframe that is characterized by principals' attendance at a series of meetings on a monthly basis. The meetings consist of two different types: whole-group seminars where every principal in the program meets together in one location for an entire day, and regional-cohort focus group meetings that consist of small groups of four to six principals whose schools are located in close geographic proximity to one another. These groups meet in a location of their choice for one half day on an alternating basis with the whole-group seminars and are led by a trained mentor.

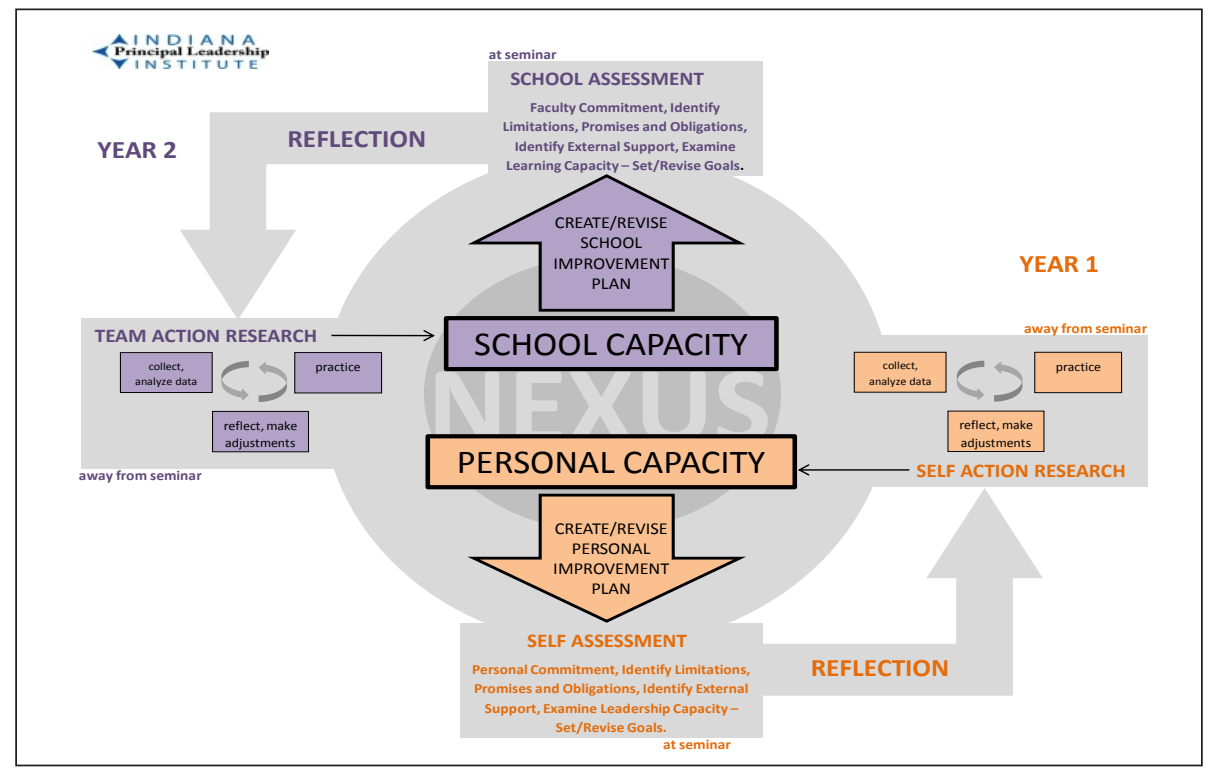

Fig. 1: IPLI conceptual framework 
IPLI believes it is powerful when leaders, who share the same issues, can meet face to face and share their stories. The alternation of whole-group and smaller group meetings enables program participants to gain a sense of trust as they become more willing to share their experiences and welcome critique from peers. Each whole-group meeting consists of presentations by nationally recognized speakers on timely topics critical to the principalship, reflection on assessment data collected for each principal by IPLI, and time in regional cohort groups to plan and implement an action research study. Each small-group regional cohort meeting also consists of activities and discussion about each principal's action research as it unfolds throughout the year, as well as time to process and make sense of new information presented at whole-group seminars and time to function as a support group for one another.

Each year, approximately 50 principals, nominated by a district-level supervisor, are selected to participate. Preference is given to principals with three or more years of experience, and every effort is made to ensure that the state is represented geographically, demographically, and academically (A-F school rating). ${ }^{1}$ Once selected, principals are divided into regional focus-cohorts and assigned a mentor.

Individuals interested in being an IPLI mentor must be nominated and are then chosen by a selection committee, through an extensive review process. IPLI mentors, consisting mainly of current practicing principals as well as some superintendents who have demonstrated excellence in school leadership, receive training, which includes specific preparation on how to coach the action research process. Once a month support is also provided for the mentors to scaffold their coaching of the action research process in the form of a newsletter with tips and ideas for facilitating action research at each regional cohort meeting as well as readings and other materials to support coaching (Dana \& Yendol-Hoppey, 2008; Dana, 2013). Mentors reported that this support enabled them to effectively coach and minimized any struggles they had in enacting their role as mentor.

As previously stated, mentors meet monthly with their regional focus-cohorts and also conduct at least two site visits to each principal's school during the year. The role of the mentor is critical, and IPLI expects mentors to create, develop, and maintain an effective, professional mentoring relationship with IPLI principals. In addition, mentors are expected to facilitate meaningful conversations, ask the tough questions, and support each principal at and away from the seminars. As information is shared either by guest speakers or through other venues at seminars, mentors are required to help principals process that information into meaningful and usable knowledge. 
In addition to the whole-group seminars and regional focus-cohort groups led by a mentor, participation in IPLI includes access to IPLI resources to support the needs of principals and their schools; involvement in the Marzano High Reliability Schools ${ }^{\mathrm{TM}}$ Network; membership in the Indiana Association of School Principals; registration for the Indiana Association of School Principals Fall Conference; registration for the Ed Leaders Network, an Internet-based, on-demand professional development for school leaders ${ }^{2}$; an opportunity to enroll in 12 university credits toward the Indiana State University Educational Specialist's program at a significantly reduced tuition rate; and 45 Professional Growth Plan (PGP) points for state licensure renewal for each year of participation. In addition, during the second year of the program, IPLI supports the attendance of two teachers for each principal at every whole-group seminar. In this way, teachers become action research partners with their principals during year two of the program, which focuses on whole-school improvement. In contrast, during year one, principals focus their action research on their own personal leadership development. It is this initial action research experience that is the focus of this article.

In April of 2015, IPLI graduated its first cohort of 56 principals and 11 mentors. Cohort 2, consisting of 57 principals and 13 mentors, has begun its second year with over 100 teachers participating in the whole-group seminars with their principals. On July 14, 2015, IPLI welcomed its third cohort of 62 principals and 11 mentors. This article reports on the year one action research experiences of Cohort 2 principals, as it was not until year two of IPLI that the IPLI action research model was fully developed and implemented.

\section{The IPLI Action Research Model: Year One}

Year one action research experiences for IPLI principals begin with a two-day July institute on the Indiana State University campus. The institute includes an introduction to and overview of IPLI, time for regional cohort members to meet their mentors and to engage in activities that begin the development of strong relationships with one another, two to three nationally known speaker keynotes and time to debrief what they learned in each session, interaction with the previous IPLI principal cohort, and an extensive action research kickoff. The kickoff begins with a two-hour interactive introductory session that includes a presentation explaining the foundations and value of the process, an overview of each phase of action research (developing a wondering or research question, collecting data, analyzing data, taking action, and sharing one's learning with others), and extensive examples of action research completed by teachers 
and principals both locally and across the nation. This action research introductory session takes place on the first day of the institute.

On the second day, principals from the previous cohort present their action research in a conference-like format, enabling the new first-year IPLI principals to choose two specific examples of action research to learn about that were completed within the IPLI professional development program. Next, the new principals are introduced to the IPLI action research mini-cycle, designed to help the principals develop an initial "feel" for the process and the meaning it could have for their practice. The IPLI action research mini-cycle consists of five options, each requiring approximately 60-90 minutes of a principal's time prior to the next whole-group seminar in September. The topics cover the value of Twitter, webinars, and literature for a principal's practice, as well as time and stress management. Each option is presented using the language of action research: wondering, action, data collection, data analysis.

To exemplify, the first two options for the IPLI action research mini-cycle appear below:

\section{SAMPLE AR MINI-CYCLE OPTIONS}

Option One: Twitter as a Learning Tool for Principals. Follow 3-5 educational leaders between now and the September seminar. Keep a brief log of their tweets and what they make you think about in relationship to your own instructional leadership practice as a principal. Their tweets become your "data" to answer the question, "In what ways can following distinguished educators on Twitter inform my practice as an instructional leader at my school?" Bring your log with you to our September seminar and be ready to "analyze" this data; share who you followed and what you learned with your cohort members.

Option Two: The Value of Webinars for Administrative Practice. Watch webinars on Ed Leaders Network (most of these are 10-15 minutes in length) to learn more about topics of interest to you. Watch a total of 3-5 Webinars (approximately one a week over time) between now and the September seminar. Keep a journal to track your learning from these webinars. After each webinar viewed, complete a short journal entry using these prompts: "In what way did this webinar impact my learning as a principal?," and "What, if anything, might I do in my school as a result of watching this webinar?" These journal entries become your "data" to answer the question, "What is the relationship between my participation in short 10-15 minute webinars approximately once a week and my administrative 
practice?" Bring your journal with you to our September meeting and be ready to "analyze" this data and share the webinars you watched and what you learned as a result with your cohort members.

At the July meeting, throughout all of the activities named above, principals sit in their regional cohort groups and time is built in throughout the institute for mentors and principals to begin to develop positive working relationships with one another. One activity completed by each regional cohort group is called "Forming Ground Rules,"3 where each group creates norms for its work together. One important norm developed and adopted by each group focuses on confidentiality-what happens in the group discussion stays in the group discussion to ensure principals can freely share their dilemmas, issues, and tensions of practice that lead to their action research without fear their honest exploration of their practice will be reported to their supervisors back in the home district. Ground rules are reviewed at the start of each regional cohort meeting throughout the year.

At the August regional cohort group meeting, mentors check in with their principals on AR mini-cycle option choices and progress made to date. At the whole-group September seminar, principals are led through a data analysis exercise and provided the opportunity to summarize and share their mini-cycle learning with others both within and outside of their own regional cohort group.

After the mini-cycle is completed at the September seminar, the principals are introduced to the process of planning a personal cycle of action research that begins at the October regional cohort meeting and culminates in April, when the principals present their action research to one another at the last whole-group seminar of the year (Click Here to See Personal Action Research Schedule). In addition, principals receive three sets of data to assist them in the development of their wondering:

- Results from the School Culture Survey (Gruenert \& Valentine, 1998) administered to building-level administration and teachers and staff;

- Results from an IPLI Leadership Survey based on the national standards for school leaders administered to building-level administration and teachers and staff; and

- Results from Carol Dweck's “What's My Mindset” (Mindset Works, Inc., n.d.). 
The regional cohort mentors, who have participated in an eight-hour training on coaching action research and receive monthly newsletters and readings on the topic, carefully scaffold their principals through the personal action research cycle. At the regional cohort meeting in October, they engage principals in developing and finetuning their wondering or research question with a particular emphasis on focusing the principals during year one on the development of a question that explores their own personal leadership practice. With a question developed in October, the principals prepare a one- to two-page action research plan they bring with them to the November seminar to receive feedback on from their mentor and regional cohort peers. Data collection begins after this process.

The January regional cohort meeting is a time for mentors to check in with their principals on data collection and answer any clarifying questions about action research. February and March meetings are reserved for principals to bring data from their action research to these meetings and receive support from their regional cohort groups in formative and summative analysis. The March meeting also includes time to develop a title and abstract of each principal's research to be printed in a program for the Action Research Sharing Showcase at the April whole-group seminar ${ }^{4}$ and directions for preparing a 10-minute PowerPoint presentation for this purpose.

Principals present their action research to one another in April in a series of three, 30-minute round-table sessions with two principals presenting on related topics at each table each session. When not presenting, principals attend the sessions of others, choosing from many selections from the showcase program. The showcase ends with a celebration of learning at which time each principal is recognized and receives an "action research pin" to commemorate the learning that has occurred through the principal's first full cycle of the action research process.

\section{AR Projects and Feedback}

Principals found their action research "wonderings" using their IPLI data: a selfassessment of their personal leadership capacity, a non-evaluative staff survey that rated their performance based on the national standards for principals, and a selfassessment about their growth mindset. In addition, seminar topics and professional books given to IPLI participants stimulated self-reflection. The 2015 showcase topics illustrate how these principals chose to focus their inquiry wonderings (Table 1). 
Table 1

IPLI Showcase Inquiry Topics

\begin{tabular}{|c|c|c|}
\hline \multicolumn{2}{|c|}{$\begin{array}{c}\text { PRINCIPALS' WONDERINGS: } \\
\text { DILEMMAS, PROBLEMS, ISSUES, TENSIONS }\end{array}$} & $\begin{array}{l}\text { TOPIC } \\
\text { FREQUENCY }\end{array}$ \\
\hline \multirow{7}{*}{$\begin{array}{l}\text { Focus on } \\
\text { Leadership } \\
\text { Style } \\
29 \%\end{array}$} & $\begin{array}{l}\text { Developing a Culture of Shared } \\
\text { Decision Making and Distributed } \\
\text { Leadership }\end{array}$ & 5 \\
\hline & $\begin{array}{l}\text { Becoming a Leader Others Want to } \\
\text { Follow }\end{array}$ & 4 \\
\hline & $\begin{array}{l}\text { Shifting From Manager to Instructional } \\
\text { Leader }\end{array}$ & 2 \\
\hline & $\begin{array}{l}\text { Effective Time and Calendar } \\
\text { Management }\end{array}$ & 2 \\
\hline & Motivating and Supporting Students & 2 \\
\hline & Shifting to Positive Discipline & 1 \\
\hline & Dealing With a New School Placement & 1 \\
\hline \multirow{5}{*}{$\begin{array}{c}\text { Focus on } \\
\text { Instructional } \\
\text { Guidance } \\
38 \%\end{array}$} & Effective Instructional Coaching & 8 \\
\hline & Developing Relevant Instructional PD & 4 \\
\hline & $\begin{array}{l}\text { Increasing Time and Strategies for } \\
\text { Supporting Teachers }\end{array}$ & 4 \\
\hline & Navigating the PLC School Model & 3 \\
\hline & Enhancing Curriculum Coherency & 3 \\
\hline \multirow{4}{*}{$\begin{array}{c}\text { Focus on } \\
\text { Continuous } \\
\text { Improvement } \\
21 \%\end{array}$} & $\begin{array}{l}\text { Improving School and Organizational } \\
\text { Culture }\end{array}$ & 6 \\
\hline & Encouraging a Growth Mindset & 3 \\
\hline & Nurturing Data-Driven Practice & 2 \\
\hline & Fostering Authentic Collaboration & 1 \\
\hline \multirow{3}{*}{$\begin{array}{c}\text { Focus on } \\
\text { Connections } \\
12 \%\end{array}$} & $\begin{array}{l}\text { Using Social Media for Creative } \\
\text { Communication and Controlling the } \\
\text { Message }\end{array}$ & 4 \\
\hline & $\begin{array}{l}\text { Improving Communication With } \\
\text { Parents and Family Involvement }\end{array}$ & 2 \\
\hline & Networking With Other Principals & 1 \\
\hline $100 \%$ & Total Showcase Presentations & $58^{5}$ \\
\hline
\end{tabular}


While some principals focused on organizational problems, school climate, and the need to network electronically, most dealt with dilemmas and tensions related to their changing roles and authority in the schools. Leadership style makes a difference, and $29 \%$ chose to analyze their leadership confidence and credibility. While some explored digital leadership, others worked on projecting positivity and using positive discipline with students. A few tried rearranging their calendars to make more time for critical conversations with staff, and others adjusted decision-making to redistribute leadership in hopes of creating a healthy and viable school culture.

Effective instructional guidance presented challenges for $38 \%$ of the principals. They focused on instructional coaching by building a more extensive repertoire of instructional strategies, keener observational skills, and stronger collegial relationships. They considered how to tap into available community resources in order to make professional development affordable and peer coaching both relevant and possible.

For $21 \%$, they explored how to foster the attitudes and actions needed to nurture continuous improvement in their schools. Acknowledging avoidances, questioning assumptions, identifying roadblocks, imagining what could be, inspiring innovation, measuring the impact of change-these growth-mindset discussions became agenda topics with their staff.

The remaining $12 \%$ examined their communication habits and how to build better internal and external networks. They investigated how to use social media-Twitter, Facebook, school websites, newsletters-to portray a positive image of their schools, to connect with families, and to stay informed about professional trends and resources.

After the showcase, the principals responded positively when asked on an IPLI survey, "Based on your experience in using the action research process, how comfortable do you feel continuing to use this process to increase your leadership capacity?" On a comfort scale of 1 to 10,87\% rated their comfort levels at 8 or above. Principals expressed satisfaction with their action research projects in their concluding thoughts in their April research summaries.

I believe that the action research project I completed was a very valuable experience for me both professionally and personally. It was extremely nice to take time out of a busy year and focus on something I have a passion for. I believe I have learned to be a better leader within my building. 
The action research project was good for me, because the answer to my wondering (writing a newsletter) was something that I didn't like. I didn't like them as a teacher, and I swore for years that I wouldn't do one in a school I led. Fast-forward to life after this action research project.... will never go through another school year without one.

[T] he action research journey was one of great benefit for me as a professional. Through this process, I have been able to build in time in my weekly schedule to allocate to my own professional development. I have been able to use the wide variety of resources already at my disposal to improve my knowledge, skills, and understanding of best practices in education and educational leadership specifically.

In retrospect, I view this journey as one of the most gratifying periods of my administrative career. This process has taught me to be a more patient listener, as well as a valued collaborator and team member.

I am so pleased to have conducted this action research. I feel much more equipped as the head learner and leader in my school to move forward as a true professional learning community.

The action research process was revealing and provided a meaningful chance for me to solicit input from teachers and engage in reflection on what will help us move forward as a staff. The result is a great resource that will streamline basic communication and allow us to focus on instructional practices that have the greatest impact on student learning.

IPLI believes that the learning capacity of the principal creates the foundation for the school's capacity to learn. The principals in Cohort 2 embraced the growth mindset of action research and expressed readiness to introduce inquiry into their schools, to enhance the data literacy of their colleagues, and to transform their schools' learning capacity.

\section{Reflections: Lessons Learned}

The action research work of the Cohort 2 principals during year one of the program indicates the promise engagement in action research holds to provide powerful and meaningful professional learning opportunities for administrators. While the IPLI 
professional development program is still in its infancy and we continue to document, track, and study the principals in IPLI and their action research efforts, we have already learned many important lessons about how to roll out an action research professional development program for administrators from our work in designing and implementing this experience for IPLI. In this section, we share three of these lessons learned to help others who wish to institute a program of principal action research begin the process.

\section{Lesson \#1: Start Small}

Principals are under constant stress and pressure, and often describe the pace of their work as "harried" at best. For example, principal Mike Connolly (2007) wrote about what one would see by peeking into the office of a typical principal:

What would you see? A desk piled high with papers, the telephone ringing incessantly, 40 or 50 emails screaming for attention, a line of people queuing up outside the door, and a harried principal. Most principals have not learned you can't fit 10 pounds of task into a 5-pound day. Far from being models of self-control, balance, and rationality, many principals resemble butterflies on speed pills. They can't devote sustained attention to anything. (p. 32)

Because their days are so full, when action research is first introduced to principals as a part of a professional development program, it can be met with a great deal of fear and trepidation for the time it will take to engage in the process. To ease this fear and trepidation, IPLI introduced the process to the principals in the program through their engagement in the action research mini-cycle, a small, introductory activity that required just 60-90 minutes of a principal's time between the July summer action research kick-off and the September whole-group seminar. When the action research mini-cycle was presented, the time it would take to complete the cycle was highlighted, relieving principals' concerns about time commitment before the options for the minicycle were even introduced. Starting small eased the principals into the process, and when they experienced the mini-cycle and found value in completing it, they became less apprehensive about the time it would take to complete a full, personal cycle of action research.

Barth (2001) informs us that one reason it is so difficult for school leaders to become learners is lack of time, but reminds us, "For principals, as for all of us, protesting a lack of time is another way of saying other things are more important and perhaps more comfortable" (p. 157). A good first step in introducing principals to the action research process is acknowledging that lack of time will always be an issue that confronts 
principals in all they do, and while you acknowledge time as a potential barrier to engagement in action research, make a simultaneous commitment to engage in this important and necessary work by starting small, in a way that feels manageable and not overwhelming to the principals, allowing them to gain familiarity with the process first. In so doing, principals become more willing to embrace action research as an item of importance in their daily work, and make time to engage in fully implementing the process.

\section{Lesson \#2: Anticipate the Challenge of Focusing Principals on Their Own Leadership Practice}

While starting small helps ease principals into the process and creates the conditions for principals to build a commitment to action research, once that commitment is built, it is challenging to convince principals to take the time to focus on themselves first, before they endeavor to apply the process of action research to efforts at whole-school improvement. Yet, understanding and improving one's personal leadership capacity is an important prerequisite to improving one's school.

Roland Barth (1990) draws upon the common instructions given by flight attendants on every airplane flight related to the donning of oxygen masks should there be a change in cabin pressure to explain the importance of principals focusing on their own learning. Flight attendants instruct passengers to put on their own masks first before assisting others, for if people do not take care of themselves, they will be unable to care for others. Applying this metaphor to the principalship, Barth writes:

In schools we spend a great deal of time placing oxygen masks on other people's faces while we ourselves are suffocating. Principals, preoccupied with expected outcomes, desperately want teachers to breathe in new ideas, yet do not themselves engage in visible, serious learning. Teachers badly want their students to learn to perform at grade level, yet seldom reveal themselves to children as learners. It is small wonder that anyone learns anything in schools. (p. 42)

For this reason, it makes sense for principals to focus their initial action research endeavors on themselves and their own leadership practice. However, in the habit of sacrificing themselves for the teachers and the students in their buildings, it is not surprising that many principals find it difficult to use the process of action research to take care of themselves before they use it to take care of others. Many IPLI mentors shared the challenge of coaching principals to focus their personal action research projects inward on self-understanding and self-improvement, rather than outward on 
understanding and improving teacher and student performance at their schools. IPLI Mentor Jane Rogers reflects:

It was difficult at first to encourage principals to focus on themselves during the action research process. It is typical for principals to be outward thinkers and planners. Principals, by nature, are selfless in their willingness to give their time to help and support others in the learning process. Time management often dictates that principals pay attention to details of the school day including scheduling everything from lunch, recess, busses, classes, after-school events, and more. With this in mind, the challenge of asking principals to focus on themselves could be an overwhelming task.

The IPLI process purposefully addressed this challenge in three ways. First, forming cohort groups allowed principals the opportunity to connect with a mentor and other principals in close proximity. The principals communicated with each other frequently to keep on track. Secondly, the participation in a mini-action research project allowed principals the opportunity to focus on themselves for a shortterm project. Finally, by building on the success of the action research mini-cycle, principals thought about how they could stretch this idea and enhance their leadership capacity throughout the year. Principals then crafted wonderings that would improve their leadership even while the project improved something in the school (personal communication, August 11, 2015)

In sum, it is important to anticipate that principals will need help and support in focusing the subject of their action research on themselves and their own administrative practice.

\section{Lesson \#3: Be Patient and Recognize That Out of Dissonance Comes Growth}

While IPLI principals were able to build an initial commitment to action research through the action research mini-cycle and subsequently focus their personal action research cycles on themselves and their own administrative practice through support and coaching from their mentors, mentors reported that at various times during each individual step of the personal action research process, principals would report skepticism about their projects as they were unfolding over the course of the year and wonder if, indeed, they were really learning anything of importance that would impact their work. Mentor Mike Pinto reflects: 
For some, the idea of action research is innate. Like a person who can fix a motor without a manual, they constantly reflect, re-evaluate, set goals, collect data, and start again. But for many, this concept of taking a breath and looking inward and also reflecting on each step taken is new. The value of the action research process comes in the ability to reflect. If not intentionally taught, for many it doesn't happen.

Chunking the personal action research cycle into monthly segments for the principals (developing a wondering, developing a plan for your action research, collecting data, analyzing data, and presenting your learning to others) was a great way to intentionally teach that ability to reflect. In the end, at the Action Research Showcase in April, each individual part came together into a whole, but navigating the waters that got the principals to that point was sometimes a tricky path. Principals would sometimes get bogged down in the details of each individual step of the action research cycle, and weren't yet able to see their projects as a whole.

It's the difference between a microscopic and a 30,000-foot view many times along the way. Individuals would get bogged down on the minutia and not understand how each step led them up the staircase. It wasn't until they shared their action research at the April Showcase that they could actually see and appreciate the action research road they had traveled and view the action research of others as well. Sometimes seeing someone else's work makes your work more meaningful. (personal communication, August 10, 2015)

It became an important job of the IPLI mentors to provide reassurance to the principals during times when they became "bogged down" in individual components of the process, such as deciding what their "question" would be and analyzing data, a process that can feel overwhelming at the start leading to "data analysis paralysis" when principals lament, "Okay, I've collected all the stuff, but I have no clue what to do with it now!" (Dana, 2009, p. 105). The mentors' investment in reassurance during these times of struggle paid off in April when the principals presented to one another, at which time they were able to see and understand the totality, and value their learning through the process of action research. In essence, the principals had to "live through" the complete cycle once before they could appreciate each individual component of their work during this program of professional development. Sometimes, the individual steps would cause dissonance. Yet, it was out of this dissonance that growth occurred. Anticipating dissonance and persevering through it is a critical component of building a successful professional development program of action research for principals. 


\section{Conclusions}

While it is early in the development and implementation of IPLI, there is evidence that the ways action research has been incorporated into this two-year professional development program is indeed having an impact on principals as they perceive the process of action research to be a meaningful mechanism for their own professional learning. At the start of Year 2 of the program, one principal even shared her intent to introduce action research to all of the teachers in her building:

I absolutely love the action research process and buy into it...not only for administrators, but for teachers. The teacher leader that I brought to the July IPLI meeting is just as fired up about the process as I am for this year. We have brainstormed how we want to launch the idea and process to the staff in replacement of our "yearly professional goals" that get made at the beginning of the year and put on the shelf until the end of the year for review. The AR process will allow for ongoing, meaningful personal/professional development to occur. (K. Laffoon, personal communication, July 16, 2015)

In addition, one mentor has convinced her district to use the IPLI action research model with its entire leadership staff, and subsequently, the teachers in this district as well. This district is currently making plans to transform the ways professional development has historically been approached, reframing professional development as inquiry.

The purpose of this article was to provide a description of this program to share the promise action research appears to hold for principal professional development as well as to share lessons we have learned from the design and implementation of an extensive action research program for principals early in its implementation. Additional research and program evaluation efforts are underway to follow these principals longterm throughout the remainder of their IPLI professional development experience and after graduation. In year two, principals will select two teacher-leaders to join them in the study of their school and creation of an action research school improvement project. As per IPLI's conceptual model, all action research during year two will focus on increasing the school's learning capacity and will be guided by the overarching wondering: "How do we increase the learning capacity of our school?" Individual principal and teacher teams will develop their own sub-wonderings that focus more specifically on the pathway they wish to take in their schools to increase learning capacity and study the results. Partnering with Marzano Research, IPLI utilizes the High Reliability Schools ${ }^{\mathrm{TM}}$ surveys to collect school data to assist principals and their 
teachers in developing their sub-wonderings. Seminars and principals' regional focuscohort meetings center on building the learning capacity of schools through the use of professional learning communities and development of a school-wide action research project. Year two of IPLI concludes with an IPLI Showcase of Schools where each school will share its action research project. After graduation from the institute, IPLI will continue to track long-term effects of the program on principal leadership and school improvement through a longitudinal quantitative and qualitative research study. We are looking forward to following and studying these principals as they continue their work as action researchers, as well as continuing to study, reflect, and refine IPLI and the role action research plays within it based on lessons we continue to learn as the architects of the IPLI action research experience.

Principals need powerful professional development models to be developed, studied, refined, and shared to provide support for school leaders after they are hired into administrative positions. As Barth (1990) explains,

[S] ustaining the development of school leaders is crucial to the quality of life and to the best interests of all who inhabit the schoolhouse - and to their development as a community of learners. Principals, no less than teachers, need replenishment and invigoration and an expanded repertoire of ideas and practices with which to respond to staggering demands. (p. 46)

Action research is one promising practice for administrator professional development that can replenish and invigorate principals, providing them with a systematic and intentional way to respond to the staggering demands of their work.

\section{Notes}

1. The Indiana State Board of Education has adopted letter grades (A, B, C, D, and F) to indicate how well Indiana schools are performing. For more information, please see http://www.doe.in.gov/accountability.

2. Please see https://www.edleadersnetwork.org/

3. Please see http://schoolreforminitiative.org/doc/forming_ground_rules.pdf

4. Please see http://www.indianapli.org/wp-content/uploads/AR-Showcase.pdf

5. While there was a total of 57 principals in Cohort 2, one mentor voluntarily engaged in her own cycle of action research alongside the principals she was coaching in the process. This mentor's project was included in the analysis. 


\section{References}

Barth, R. (1990). Improving schools from within: Teachers, parents, and principals can make the difference. San Francisco: Jossey-Bass.

Barth, R. (2001). Principal centered professional development. Theory Into Practice, 25(3), 156-160.

Cochran-Smith, M., \& Lytle, S. L. (2009). Inquiry as stance: Practitioner research for the next generation. New York: Teachers College Press.

Connolly, M. (2007). Harried principals aren't helpful principals. Principal, 86, 32-35.

Dana, N. F. (2009). Leading with passion and knowledge: The principal as action researcher. Thousand Oaks, California: Corwin Press.

Dana, N. F. (2013). Digging deeper into action research: A teacher inquirer's field guide. Thousand Oaks, CA: Corwin Press.

Dana, N. F., Thomas, C., \& Boynton, S. (2011). Inquiry: A districtwide approach to staff and student learning. Thousand Oaks, CA: Corwin Press.

Dana, N. F., Tricarico, K., \& Quinn, D. (2010). The administrator as action researcher: $A$ case study of five principals and their engagement in systematic, intentional study of their own practice. Journal of School Leadership, 19(3), 232-265.

Dana, N. F., \& Yendol-Hoppey, D. (2008). The reflective educator's guide to professional development: Coaching inquiry-oriented learning communities. Thousand Oaks, California: Corwin Press.

Dana, N. F., \& Yendol-Hoppey, D. (2014). The reflective educator's guide to classroom research: Learning to teach and teaching to learn through practitioner inquiry, 3rd Edition. Thousand Oaks, California: Corwin Press.

Darling-Hammond, L., LaPointe, M., Meyerson, D., Orr, M. T., \& Cohen, C. (2007). Preparing school leaders for a changing world: Lessons from exemplary leadership development programs. Stanford, CA: Stanford University, Stanford Educational Leadership Institute.
Desimone, L. M. (2009). Improving impact studies of teachers' professional development: Toward better conceptualizations and measures. Educational Researcher, 38, 181-199. doi:10.3102/0013189X08331140

Garet, M. S., Porter, A. C., Desimone, L., Birman, B. F., \& Yoon, K. S. (2001). What makes professional development effective? Results from a national sample of teachers. American Education Research Journal, 38, 915-945. doi:10.3102/00028312038004915

Gruenert, S., \& Valentine, J. (1998). School culture survey. Developed at the Middle Level Leadership Center, University of Missouri, Columbia, MO.

Educational Research Service. (1999). Professional development for school principals. The Informed Educator Series. Arlington, VA: Author.

Hitt, D. H., Tucker, P. D., \& Young, M. D. (2012). The professional pipeline for educational leadership: Informing educational policyA white paper developed to inform the work of the National Policy Board for Educational Administration. Retrieved from www.ucea. org/storage/pdf/PipelineWhitePaper_web. pdf

Interstate School Leaders Licensure Consortium. (2000). Proposition for quality professional development of school leaders. Washington, DC: Council of Chief State School Officers.

Leithwood, K., Louis, K.S., Anderson, S., \& Wahlstrom, K. (2004). How leadership influences student learning. Retrieved from http://www.wallacefoundation.org/knowledge-center/school-leadership/key-research/Pages/How-Leadership-InfluencesStudent-Learning.aspx

Marzano, R., Waters, T., \& McNulty, B. (2005). School leadership that works. Alexandria, Virginia: ASCD.

Mindset Works, Inc. (n.d.). What's my mindset. Retrieved from http://www.mindsetworks. com/assess/ 
Mitgang, L., \& Gill, J. (2012). The making of the principal: Five lessons in leadership training. Retrieved from www.wallacefoundation. org/knowledge-center/school-leadership/ effective-principal-leadership/Documents/ The-Making-of-the-Principal-Five-Lessonsin-Leadership-Training.pdf

National Association of Secondary School Principals, \& National Association of Elementary School Principals. (2013). Leadership matters: What the research says about the importance of principal leadership. Retrieved from http://www.principals.org/ KnowledgeCenter/LeadershipMatters.aspx

Noffke, S. (1997). Professional, personal, and political dimensions of action research. In M. Apple (Ed.), Review of research in education (Vol. 22, pp. 305-343). Washington, DC: AERA.
Somekh, B., \& Zeichner, K. (2009). Action research for educational reform: Remodeling action research theories and practices in local contexts. Educational Action Research, 17, 5-21. doi:10.1080/09650790802667402

The Wallace Foundation. (2010). Educational leadership: An agenda for school improvement. Retrieved from http://www.wallace foundation.org/knowledge-center/ school-leadership/key-research/Pages/education-leadership-an-agenda-for-schoolimprovement.aspx

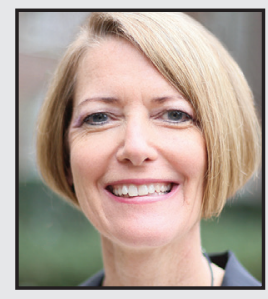

Nancy Fichtman Dana is Professor of Education in the School of Teaching and Learning at the University of Florida. Since earning her PhD in 1991, she has been a passionate advocate for the provision of meaningful professional learning experiences for educators, working with numerous schools and districts across the United States and abroad to craft professional development programs of inquiry as well as conducting research on the process. She is currently working with IPLI to develop and study a program of action research for principals. She has published 10 books and over 60 articles and book chapters on the topic of practitioner inquiry/action research. 


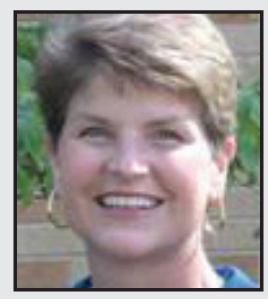

Linda Marrs-Morford is Director of the Indiana Principal Leadership Institute at Indiana State University. Before joining IPLI, she was a professor in the Department of Educational Leadership at Eastern Illinois University where she also served as Director of the New Leaders Assistance Service, a mentoring and induction program for new school building administrators. She is a former teacher, assistant principal, and principal in public schools in Texas, New York, and Illinois. Linda earned her PhD in Educational Leadership from the University at Albany, NY.

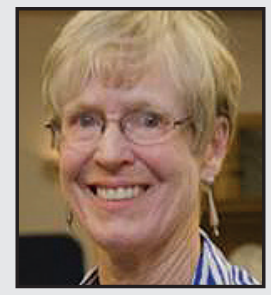

Shelley Roberts, former Director/Principal of the University of Illinois High School, is committed to teacher inquiry as a professional development and school improvement strategy. She trained action researchers for the New Mexico Center for Teaching Excellence and teaches action research at the University of New Mexico. She mentors inquiry-based Teacher Learning Communities at South Valley Academy, an innovative school that equips immigrants to be first-generation, collegebound students. Her critical ethnography, Remaining and Becoming: Crosscultural Currents in an Hispano School, analyzes the ambivalence of education: the losses and gains that education brings and what future it can and should serve. 